\title{
Introduction of Arthur L. Beaudet, Harland Sanders Award Recipient
}

James R. Lupski, MD, PhD

It is a thrill to introduce my mentor, colleague, and friend, Arthur L. Beaudet, the recipient of the 2002 Colonel Harland Sanders Award from the March of Dimes for lifetime achievement in genetic research and education.

Art was born in Woonsocket, Rhode Island. He graduated from the College of the Holy Cross in 1963 and from Yale Medical School in 1967 with honors from both institutions, including induction into AOA in his junior year of medical school. After internship and residency at the Harriet Lane Pediatric Service at Johns Hopkins University School of Medicine, he was a research associate at the National Institutes of Health for 2 years and then moved to Baylor College of Medicine in 1971, over 30 years ago. For almost a decade he has been a dynamic, visionary, and democratic leader as the Henry and Emma Meyer Professor and Chairman of the Department of Molecular and Human Genetics, and he has guided our department to being one of the top genetics programs in the nation.

During his tenure at Baylor, Art has always been an academic triple threat in research, education, and service, the last both from a patient care or clinical perspective and from an administrative standpoint. However, he never forgot his pediatric roots (Fig. 1). More than 60 postdoctoral fellows have passed through his laboratory, and more than a half-dozen graduate students have received their $\mathrm{PhD}$. His laboratory's research accomplishments have been many-fold, and Art's research interest reflects the history and maturation of the field of human and medical genetics, from biochemical genetics to gene mapping and gene discovery. In the more recent past, as the tools of molecular biology have enabled new scientific approaches, his laboratory has provided important new insights into molecular genetic mechanisms for birth defects and disease that have profoundly affected our way of thinking and also altered how we practice medical genetics. I am going to highlight one area of research in his laboratory.

In 1988 Art's laboratory published the first example of uniparental disomy (UPD) as a mechanism for human genetic disease (Fig. 2). ${ }^{1}$ Molecular studies of a patient with cystic fibrosis and short stature revealed lack of transmission of a paternal allele at the MET locus, nearby the yet-to-be-identified CFTR gene. Multiple chromosome 7 genetic markers failed to

From the Department of Molecular and Human Genetics, Baylor College of Medicine, Houston, Texas.

James R. Lupski, MD, PhD, Department of Molecular and Human Genetics, Baylor College of Medicine, One Baylor Plaza, Room 690E, Houston, TX 77030.

DOI: 10.1097/01.GIM.0000029040.40920.29 identify a paternal contribution, providing essentially unequivocal evidence for maternal UPD7. This paper proposed four mechanisms for UPD (Fig. 3), each of which has been proven to occur. The last model, "trisomy to pseudodisomy," changed the way we counseled patients with chorionic villus sampling evidence for trisomy whose subsequent amniocentesis or cord blood sampling revealed a "normal karyotype analysis."

In an editorial accompanying the original paper, Warburton $^{2}$ proclaimed that this was an intellectually interesting phe-

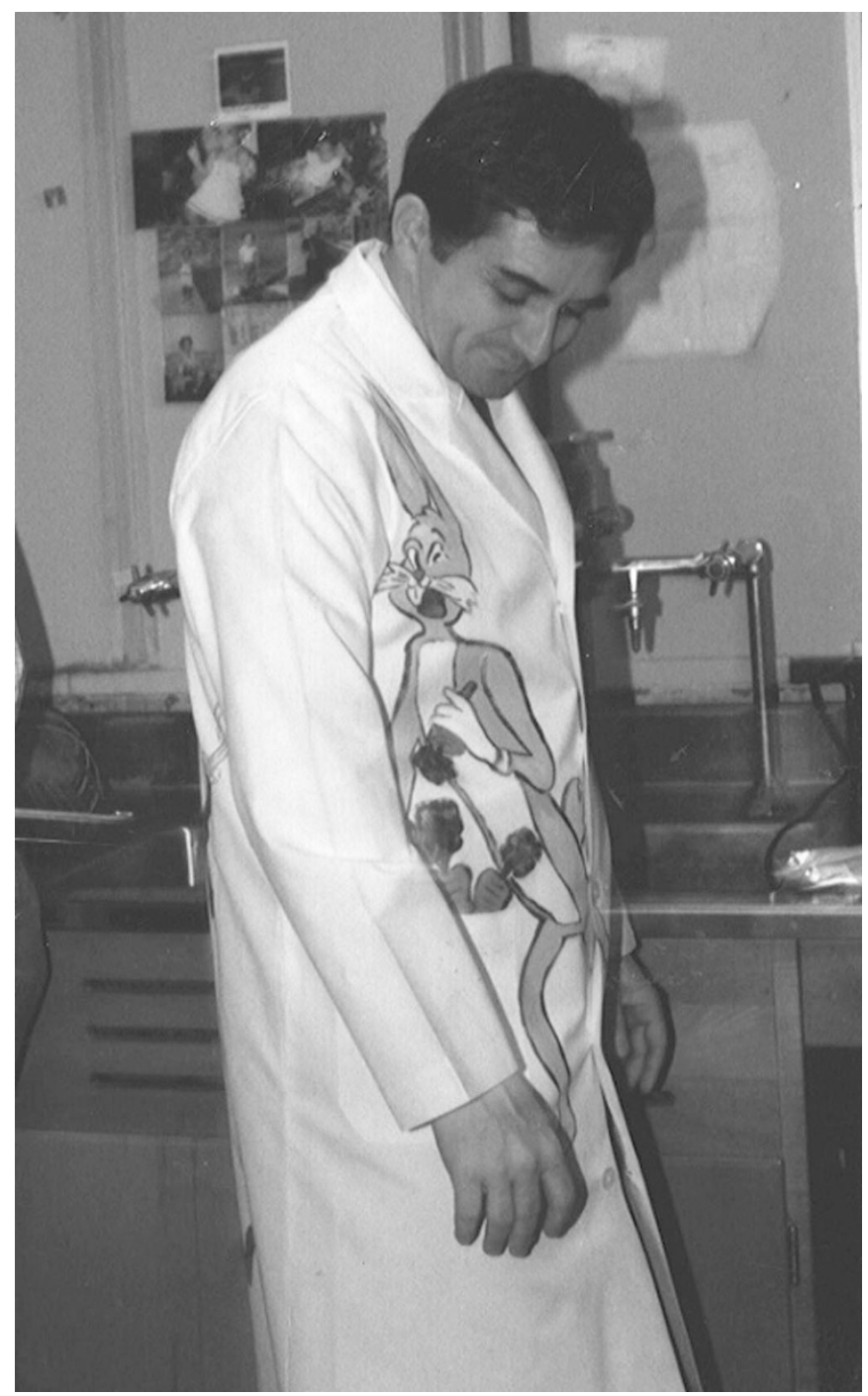

Fig. 1 Art Beaudet in laboratory attire. 

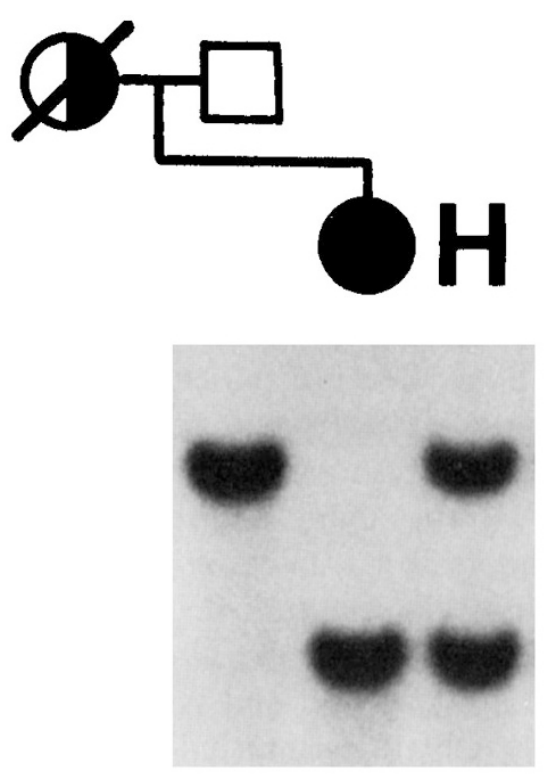

\section{$\mathrm{Taq} I / \mathrm{MetH}$}

Fig. 2 Southern blot analysis of genomic DNA from a patient with cystic fibrosis and short stature, providing the first evidence consistent with maternal uniparental disomy for chromosome 7 (matUPD7). Reprinted with permission from the University of Chicago Press. ${ }^{1}$

nomenon but not likely to occur again. However, this March issue of Pediatrics ${ }^{3}$ (Fig. 4) reviews more than 30 literature reports of matUPD7 and also reveals that genetic screening identified matUPD7 in 15\% of Russell-Silver syndrome cases and $3 \%$ of idiopathic short stature! The latter represents a not uncommon presentation in a pediatric genetics clinic. To date, UPD has been described in 19 of the 23 chromosome pairs with an abnormal clinical phenotype due to imprinting having been clearly defined for 6 chromosomes: matUPD for chromosomes 7, 14, and 15; patUPD for chromosomes 6, 14, and $15 .{ }^{4}$

Art's lab focused on genetic imprinting, particularly in relation to chromosome 15 and the Angelman/Prader-Willi syndrome region given that UPD represented a mechanism for these diseases. After identifying mutations in the UBE3A gene encoding E6-AP ubiquitin-protein ligase as the cause for Angelman syndrome, ${ }^{5}$ remarkably they demonstrated tissue-specific imprinted expression of $U b e 3 a^{6}$ in hippocampal and Purkinje neurons of the mouse (Fig. 5). These seminal studies clearly established an important role for epigenetics in human clinical phenotypes.

Art's efforts in educating all of us in human and medical genetics have been as far-reaching and impressive as the many research accomplishments. With close colleagues he has been intensely involved in editing The Metabolic and Molecular Bases of Inherited Disease 7 through 3 editions, each accompanied by a major expansion from 1-2, 2-3, and 3-4 volumes. The latest 8 th edition (Fig. 6) contains over 5000 pages! Art has directed the NIH Clinical Genetics Training Program for more than 25 years; close to 100 physician/scientists have graduated under his leadership.

I want to relate one anecdotal story to give the audience a taste for Art's involvement in this clinical training program. While I was a clinical fellow, Markus Grompe and I were on service together for a few months and Art was our attending clinical geneticist for a portion of this time. When he would

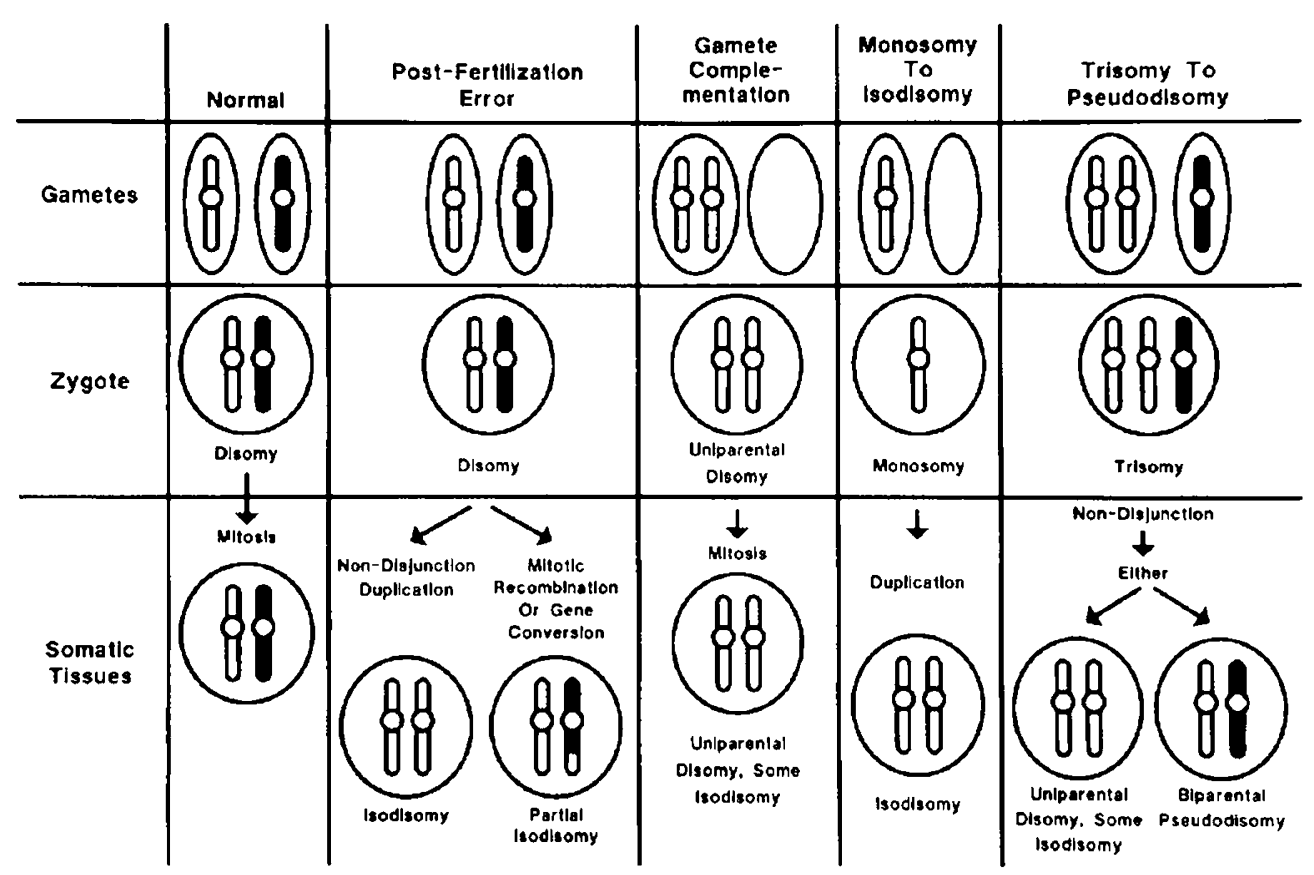

Fig. 3 Proposed mechanisms to account for the occurrence of UPD. Reprinted with permission from the University of Chicago Press. ${ }^{1}$ 


\section{Maternal UPD7}

\section{over 30 literature reports}

\section{6 of $39(15 \%)$ Russell-Silver syndrome}

\section{6 of $205(3 \%)$ idiopathic short stature}

Fig. 4 Maternal UPD7 has been identified as a cause of Russell-Silver syndrome and of idiopathic short stature.
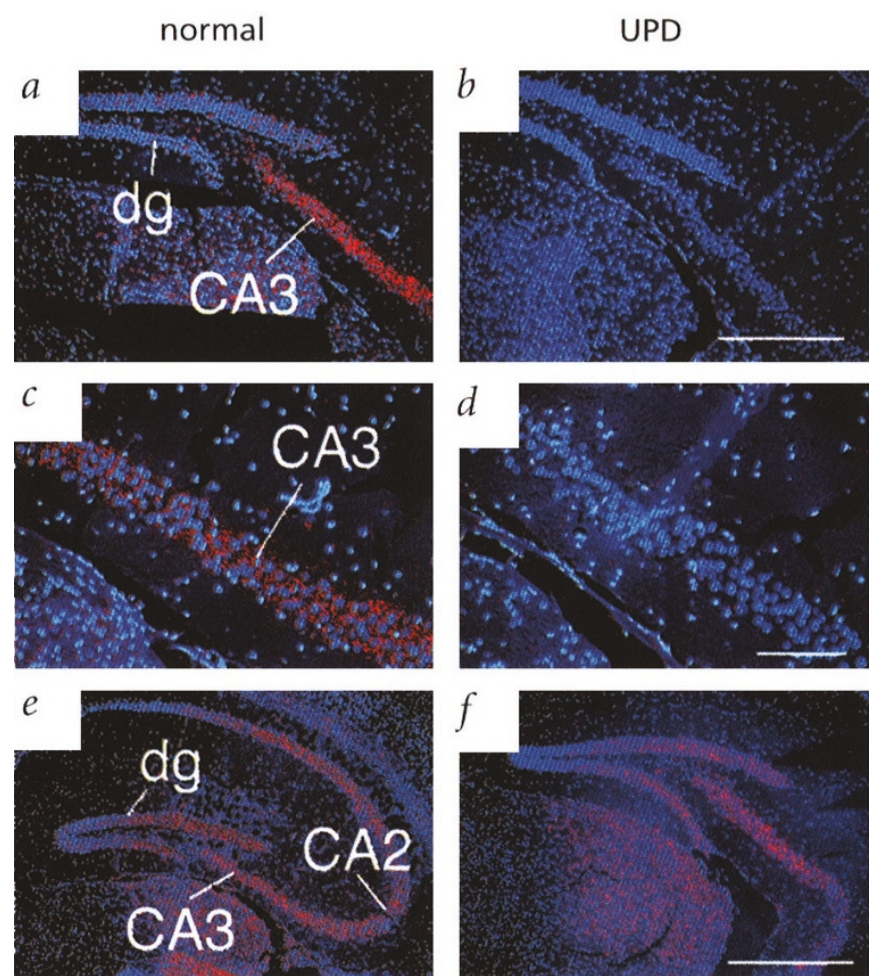

Fig. 5 Tissue-specific expression of an imprinted locus. Maternal expression (red grains in a and c) of the imprinted Ube $3 a$ locus with absent paternal expression in paternal UPD mice ( $b$ and d). A control nonimprinted locus is shown ( $c$ and $f$ ) with equal expression from normal biparental alleles as well as paternal UPD mice. Reprinted with permission from Nature Genetics. ${ }^{6}$

staff the consult and we would meet with the parents, Art would ask to see the family pedigree we had drawn and proceed to ask the parents questions regarding family history until he identified an error in our pedigree. He would then look up from over his glasses with bowed head directly at us and not say anything, but the implication was clear. We quickly learned to be compulsively accurate with each pedigree. The next time Art was our attending, we drew extensive five- and six-generation

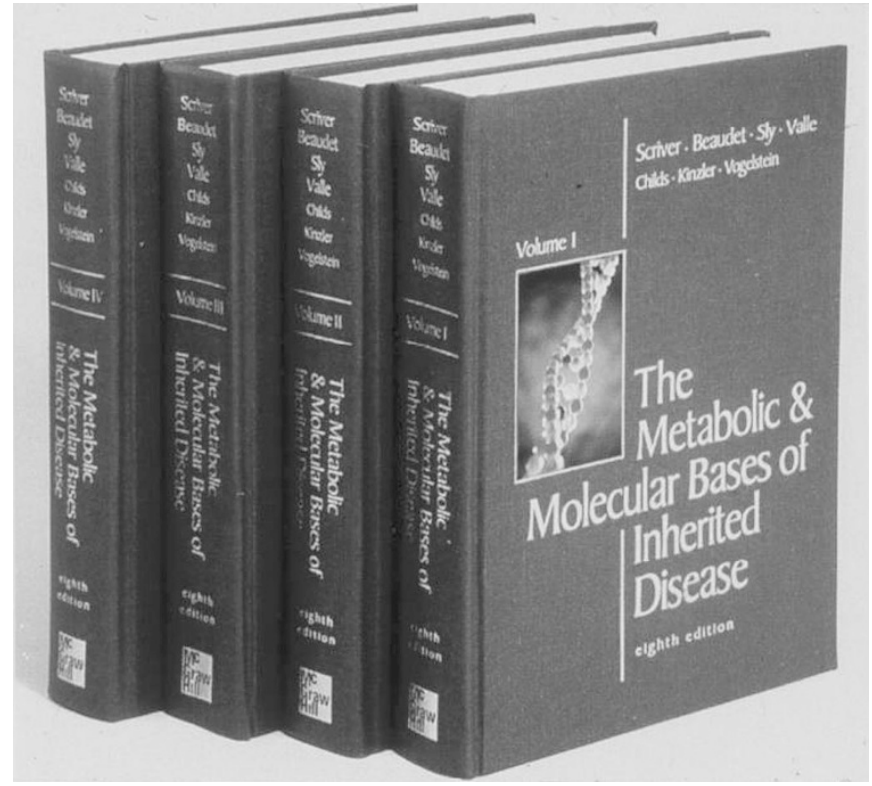

Fig. 6 The eight edition of The Metabolic and Molecular Bases of Inherited Disease (photo kindly provided by Dr. Charles Scriver, McGill University).

pedigrees with multiple family members. We thoroughly enjoyed the look on Art's face when he tested our pedigrees by asking the parents questions. It was an incredible learning experience and fun to have such a mentor available.

In closing I would like to read the citation for this year's Colonel Harland Sanders Awardee: "Whereas your original research delineated the mechanisms for UPD in human disease and the molecular basis of imprinting in disorders such as Angelman syndrome; and for training a generation of clinical geneticist through your writings and leadership in medical education."

\section{References}

1. Spence JE, Perciaccante RG, Greig GM, Willard HF, Ledbetter DH, Hejtmancik JF, Pollack MS, O’Brien WE, Beaudet AL. Uniparental disomy as a mechanism for human genetic disease. Am J Hum Genet 1988;42:217-226.

2. Warburton D. Uniparental disomy: a rare consequence of the high rate of aneuploidy in human gametes. Am J Hum Genet 1988;42:215-216.

3. Hannula K, Lipsanen-Nyman M, Kristo P, Kaitila I, Simola KO, Lenko HL, Tapanainen P, Holmberg C, Kere J. Genetic screening for maternal uniparental disomy of chromosome 7 in prenatal and postnatal growth retardation of unknown cause. $\mathrm{Pe}$ diatrics 2002;109:441-448.

4. Engel E, Antonarakis SE. Genomic imprinting and uniparental disomy in medicine: clinical and molecular aspects. New York: Wiley-Liss, 2002.

5. Matsuura T, Sutcliffe JS, Fang P, Galjaard RJ, Jiang YH, Benton CS, Rommens JM, Beaudet AL. De novo truncating mutations in E6-AP ubiquitin-protein ligase gene (UBE3A) in Angelman syndrome. Nat Genet 1997;15:74-77.

6. Albrecht U, Sutcliffe JS, Cattanach BM, Beechey CV, Armstrong D, Eichele G, Beaudet AL. Imprinted expression of the murine Angelman syndrome gene, Ube3a, in hippocampal and Purkinje neurons. Nat Genet 1997;17:75-78.

7. Scriver CR, Beaudet AL, Sly WS, Valle D, Vogelstein B, Childs B. The metabolic and molecular bases of inherited disease, 8th ed. New York: McGraw-Hill, 2001. 